\title{
Hunch Mining: Intuition Augmented with Cognitive Computing, Analytics, and Artificial Intelligence
}

\author{
H. James Nelson \\ Director, SIU Pontikes Center for \\ Advanced Analytics and AI \\ actjn@siu.edu
}

\author{
Terry Clark \\ Dean, College of Business \\ Southern Illinois University \\ tclark@business.siu.edu
}

\author{
Ian Stewart \\ Presence Health \\ Ian.Stewart@presencehealth.org
}

\begin{abstract}
Hunches are important tools for executives making time-critical highly complex decisions in turbulent environments. However, hunches are also elusive and exist below the surface when not being used for immediate decision making. These latent hunches can be useful for developing analytical models. This paper coins the term "hunch mining" to describe the process of surfacing latent hunches from corporate decision makers as well as workers and using them as models for data analytics. We present the Organizational Hunch Matrix and show how organizations can make the leap from time-consuming manual cognitive analysis to artificial intelligence and analytics driven analysis facilitated by Cognitive Computing Engineers.
\end{abstract}

\section{Introduction}

Executives often turn to intuition when they must make time-critical highly complex decisions [11]. There is a considerable and growing body of research that explores intuition and its role in decision making in turbulent environments [21], and intuition is seen as a key differentiator between successful top executives from lower level managers [1].

However, virtually all this research examines the use of hunches and intuition in connection with decision making. This paper explores surfacing latent hunches, those hunches that are not being used for immediate decision making but can be exploited for building models useful for data mining and data analytics.

Intuition is often dismissed as an "irrational mystical force" [5]. Intuitive hunches arise seemingly out of nowhere. They are cognitive leaps that seem right although there is no actual data to back them up. In fact, intuition is the mind's form of data mining. It is most often defined as "the act of cognition without rational inference." It is a way of learning that takes place beyond consciousness where a decision-maker acquires knowledge but is unable to identify the source of this knowledge [25, p. 98]. Experts spend a lifetime acquiring data (knowledge) that intuition sometimes forces to the surface as "hunches." While the legal definition of a hunch is "subjective, generalized, unreasoned and therefore unreliable" [22, p. 407], we use the definition derived from cognitive science that a hunch is the product of intuition, which is "a capacity for attaining direct knowledge or understanding without the apparent intrusion of logical inference" [37, p. 77]. When captured, hunches can serve as a valuable source for grounded business data analytics models.

The key to effective data analytics is an accurate, minimal, grounded model (see Figure 1). Models can be generated from any amount of data, and the temptation is to use as much data as possible. However, to be accurate each data element must be acquired, cleaned, stored, maintained, and eventually retired. And so the second criteria must be used: the model must be minimal to ensure that only the most important data is used. There's a point in model building where more data does not yield better results.

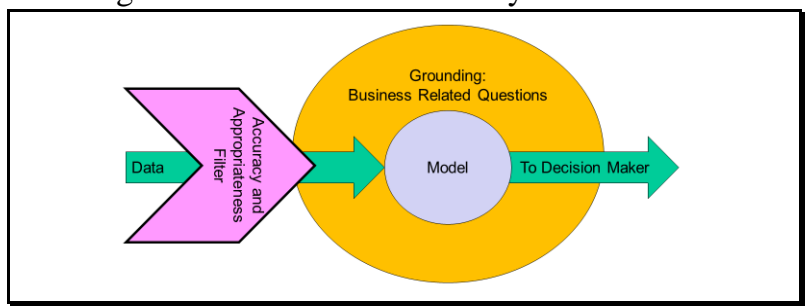

Figure 1. Accurate, minimal, and grounded models.

Finally, the model must be grounded. That is, it must be inspired by a business-related question and the results must be understood by the business. Without this grounding, executives fall into the trap of blindly following recommendations of incomprehensible models with no real understanding of what they are doing. We return to the age of the computer said we should do this, and it must be right.

Automated analytics is one of Gartner's list of strategic technologies primarily because "We simply 
don't have enough people to analyze all the data and make all the decisions and take all the necessary actions. And even if we did, they would take way too long to do these things" [13].

There are descriptive models that show what happened, predictive models that show what can happen, and prescriptive models that suggest what we should do.

However, analysts and automated analytics often lack the context for framing the model and when presented with these models the decision makers often don't know what to do with them. The analytical models explain relationships in the data, but are presented in terms that the decision makers are unfamiliar with. The cost of missing or misinterpreting models can run into the billions [12]. Models drive analytics, but no matter how many you have and how complex they may be, they need to be understandable and must be understood. We are in the earliest days of understanding how to build models at a corporate scale, and we need to realize that it's not how fast we can build models or how many models we can create that matters. What matters is how we make sound decisions based on them [14].

We live in a time where we have far too much data and we have far too few experts who can make sense of it. Approximately 50,000 gigabytes of data per second is generated worldwide. $90 \%$ of that data is unstructured: pictures, videos, audio, text, and so on. eBay has a 90 petabyte $(90,000$ terabyte $)$ data warehouse. Most large companies have several petabytes of data that can be mined. The problem is that even large companies have perhaps a dozen top strategic executives. For example, Boeing has 144,800 employees and only 50 Presidents, Senior Vice Presidents, and Vice Presidents to set the overall strategic direction of the company [7].

An organization's experts, whether executives at the strategic level or workers at the tactical level, are in the best position to propose questions that can be explored with data analytics. They know their organization, know its direction, and should be able to ask the questions that will guide them to making good decisions. Unfortunately, experts run out of questions to ask very quickly. They are limited by their world view and constrained by their mental models [30, 32]. Their mental models act as blinders to anything "outside the box" [41].

Mental models are vital for understanding, organizing, and responding to our world [4]. We create mental models from our previous experiences and are indispensable to understanding the world because they organize our knowledge in simple and robust ways "in a world awash with information of staggering complexity" [43, p. 200]. However mental models are also limiting as they channel people into selecting and using data that confirms and then reinforces existing models [15].

While mental models channel and limit (to some degree) conscious thought, the mind is also unconsciously collecting, interpreting, and analyzing data from a vast array of diverse sources. This "conglomerate of perceptual, affective, and cognitive processes" form the "rapid, unconscious, nonlinear information processes" known as intuition [24, p. 709]. Intuition is an essential management trait [31] that can bypass the limitations of executives' mental models and help them form the questions that can be delivered by business data analytics.

The "hunch" is what emerges from the unconscious intuitive processes. It's the nagging feeling that we know something but can't quite figure out why we know it. That hunch, when put to use, is a powerful tool for directing business analytics efforts.

\section{That "gut feeling"}

There are many words for intuition: hunch, gut feeling, seeing, insight, and "sixth sense" among others. Intuition is not rational; is not analytical. Intuitive decisions seem to come out of nowhere, and there is no data that someone can point to and say that's what the decision is based on. Yet intuition is gaining importance as a key factor in decision making $[23,34]$.

Intuition is hard to define and hard to analyze because it is not rational. We define rational thought as clear, well-defined knowledge and logical, analytical processes to arrive at carefully reasoned conclusions producing expected results [6].

A goal is defined, all alternative paths are uncovered and developed, extensive scanning of the internal and external environment is performed, alternatives are considered, evaluated, and weighted, and finally a "choice" is made.

Intuitive thought uses internal, tacit knowledge and unconscious processes to arrive at conclusions that often produce unexpected but welcome results. We are constantly learning and unconsciously collecting data from our environment. Experts in an area can take this data and abstract it, categorize it, and integrate it into their existing knowledge. Then, as situations arise, intuition is triggered and they unconsciously recognize and understand patterns and relationships in the apparently unrelated facts $[37,38]$.

An expert who has been in an organization for a while will develop the capacity to unconsciously collect and process data to develop his or her intuitive decision making. But to come to the surface, that intuition must be triggered [38]. This is the problem: 
the expert doesn't know what he or she needs to know to make an intuitive or even a rational decision.

This is where hunch mining becomes useful. The executive has the organizational knowledge that, when triggered, leads to a hunch. The hunch is grounded in that knowledge and leads to the development of an analytical model. The analytical model directs the organization's data mining and data analytics processes which leads to results that can be interpreted through the executive's tacit knowledge. The results can then be shared with those who don't have the insight along with the data that justifies the results of the analysis.

The trick is to trigger and capture the hunches, find them in a sea of rational discourse, and then render them into analytical models.

\section{Four kinds of organizational hunches}

An organization has two kinds of goals: tactical and strategic. Tactical goals are short range and short duration [18]. Tactical tasks form the business processes of the organization, and supporting data is found in organizational databases and enterprise systems. Data to support the tactical goals is (hopefully) structured, well-managed, and easy to obtain. On the other hand, strategic goals are long term and are the milestones that the organization uses to achieve its mission. Data to support the strategic goals is found primarily outside the organization. It is usually diverse, messy, incomplete, contradictory, often highly unstructured, and difficult to find.

The person making the hunch has two kinds of knowledge: explicit and implicit. Explicit knowledge is knowledge that has been externalized. It is easily broken down into rules, easily verbalized, and easily transmitted. It is knowledge embedded in procedure manuals, textbooks, and so on.

Implicit knowledge is knowledge that has been internalized. This knowledge is often experiential and is very difficult to transfer to others. A person may be able to perform a task based on implicit knowledge, but cannot express knowledge explicitly and cannot articulate the "rules" for how the task should be done.

Tactical and strategic, explicit and implicit define the four kinds of organizational hunches as shown in Figure 2.



Figure 2. Organizational Hunch Matrix (OHM).
The Knowledge Level axis ranges from explicit knowledge (easy to codify and to transmit) to implicit knowledge (internal and experiential). The Organizational Level axis ranges from tactical (local and immediate) to strategic (long range and long term).

Tactical hunches can be used for identifying models for making the organization more efficient. With explicit tactical hunches, the data is fairly straightforward to get from corporate data warehouses and the model can be easy to define. Both the cause and the effect are clearly stated in the hunch, such as: "I think that all work and no play makes Jack late for work." Implicit tactical hunches also use operational data but the model is much more difficult to define. The cause is stated but the effect is less well defined: "I think that all work and no play makes Jack a lazy boy" with lazy undefined and may be a very abstract concept.

Strategic hunches deal with organizational effectiveness. The data is much harder to find. It is in both organizational data warehouses and in formal and informal organizational communications, and conversations. Data can also be found outside the organization in newspapers, social media, and many other forms. Like explicit tactical hunches, the model can be easy to define and implicit strategic hunches are difficult to define.

\section{Hunch mining method}

Analytical models are in the form of "if $x$ then $y$." The three variations of the general model are shown in Table 1.

Table 1. Types of models [42].

\begin{tabular}{|l|l|}
\hline Descriptive Model & $y$ because of $x$ \\
\hline Predictive Model & If $x$ then $y$ \\
\hline Prescriptive Model & If we do $x$ then we'll get $y$ \\
\hline
\end{tabular}

These are causal models: $x$ (the cause) results in $y$ (the effect) in the past, present, or future. The first step in hunch mining is to identify causal statements in a transcript. We used a variation of revealed causal mapping techniques $[27,28]$ to identify causal statements in text. Revealed causal mapping is ideal for this task since it specifically extracts causal relationships that exist in the subjects' minds [3, 16].

Fifty Chief Information Officers (CIOs) and senior IT managers participated in the interviews we used for finding the strategic hunches. They ran the information systems function for companies ranging in size from a few hundred to many thousands of employees. None of the companies had information technology as their primary product and were in industries such as energy, manufacturing, financial services, police, and so on. We also interviewed 88 
programmer / analysts from those same companies to find tactical hunches.

The interviews were open-ended with probes [36], and were conducted both in person and or by telephone. To narrow the range of answers we focused on issues surrounding the transitions that face managers and workers in IT shops: past, present, and future. Each interview took approximately 45 minutes and was taped and transcribed. Summaries of the interviews were sent to the subjects to allow them to review and revise their comments and to ensure accuracy and to completely capture their ideas.

The first step in hunch mining is to identify the causal statements in the interviews. We started with keywords such as "if-then," "because," "so," and so on, and then performed additional analysis to identify and extract the causal elements that may be separated by several lines of text. This process was performed by a team of twelve research assistants under the supervision of the author. Two research assistants were randomly assigned to each transcript. The extracted causal statements were examined for consistency, and any differences were resolved by discussion and the senior researcher.

The analysis of the $50 \mathrm{CIO}$ transcripts identified a total of 2,769 causal statements and the analysis of the 88 Analyst transcripts identified a total of 4,832 causal statements.

\subsection{Intuitive vs. definitive causal statements}

For the second step, we examined each of the causal statements to determine if it was intuitive (indicating a hunch) or definitive. Most of the causal statements were definitive in the general form: "this is how it is." The speculative causal statements often have keywords that indicate the subject is uncertain or has doubts about the causal relationship. These are "reasoning words" that indicate speculation or making a proposal [40] and include words and phrases such as: if, should, could, would, may, "I think," and might.

\subsection{Explicit vs. implicit causal statements}

In the third step, we determined if the causal statement was explicit or implicit. An explicit causal statement comes in the general form: $x$ therefore $y$. There is an explicit causal relationship between $x$ and $y$ that the subject knows and can verbalize. This causal statement leads relatively directly to an analytical model since we know what both $x$ and $y$ are. On the other hand, implicit causal statements are formed from the CIO's tacit knowledge and are much more difficult to verbalize [29]. There is a causal relationship but it's unclear. The $y$ may be known, but the $x$ is not: " $y$ is happening but I don't know why." This leads to data mining to discover the factors that lead to $y$. Tactical vs. strategic has been described above. For example:

Well, one of the things I think that IT needs to do in general.... and I'm not talking about XXX, you do in general very much better, is they need to be more of somehow... you still have your technical resources but you need to be able to farm things out to do them quickly.

This is an explicit tactical speculative causal statement: outsourcing leads to time efficiencies. This statement is interesting as it is a source of much debate in information technology research [9]. Even if it was generally true, it may or may not be true in that CIO's organization. Data can be collected and analyzed, and the result can indicate if outsourcing truly does lead to time efficiencies.

On the other hand, a division IT manager of a Fortune 20 manufacturing company stated:

We are trying to fix that problem of people jumping from technologist to management. Some of my group and I are in the thick of it and I guess I'm leading the team or co-leading the team. We're pulling together a proposal for a legal set of definitions around career paths in IT that explicitly address that issue. We have had a technical specialist program. It was corporately administered. It was based around academic criteria. It failed to meet its ends as far as IT is concerned and so, delivering the career paths and so, we're had to pursue these things outside the process on an exception basis and we have some work to do.

This is an implicit strategic speculative causal statement. The technical specialist program didn't work and the CIO doesn't know why.

\section{Hunch mining results}

Experts have limited time for explicit thought. Their time is much too valuable and there is too much to do for them to think of more than a few models that can be fed to data analysts and data miners. Hunch mining is a method of finding analytical models that lie in the experts' tacit, unconscious mind.

We manually hunch mined 50 CIOs who were asked to think about past, present, and future transitions that their personnel and their IT functions face. We found 791 speculative causal statements within the 2,769 causal statements mentioned. We categorized them into Strategic Explicit or Strategic Implicit speculative causal statements. 


\subsection{Strategic explicit}

The most common concern across the CIOs was the uncertainty of the business climate and how it would affect the internal IT function of their organizations. Thirty four of the fifty CIOs mentioned outsourcing but few really knew what outsourcing would achieve for their organization. They did have hunches that could be translated directly into analytical models that could examine organizational efficiency. With outsourcing being a strategic decision and the direct translation to a model, these hunches were classified as Strategic Explicit.

There were two primary kinds of efficiency hunches: time and money. The larger IT departments with more than 500 employees tended to focus on shortening delivery time whereas small IT departments with less than 500 employees tended to focus on saving money. The larger IT groups knew why they outsourced and there was little speculation. From the CIO of a 4,000 employee bank:

It's the technology that we didn't have a lot of experience with and we've in the past, had a few projects that needed to be done very, very aggressively in terms of the time frame and we've outsourced them.

There was much more speculation within the IT groups of smaller (less than 500 employee) organizations. There was outsourcing but they weren't sure what they were getting out of it.

We suspected it was an outsourcing, but no one would say. In other words, no clue as to exactly what the vision was. I'm not sure they knew. It had a lot more to do with cost cutting than technology, I think.

I think that outsourcing is much more effective way to do it. For example, we've outsourced the day to day operation on the data center floor. XXX got the contract for all three of our major data centers. Three of our four data centers are now run that way and the fact that we did this over a period of about two or three years building up to this. Term employees is what we call them or contracted people and so that when the big day came and we went out on our RFP and hired one company to take on the whole thing, our people were not exposed. We have longer-term career employees this way.

Despite years of study, whether IT outsourcing saves money is still an open question with few studies that empirically examine the cost savings of IT outsourcing [20]. While IT outsourcing can save money due to the vendor's production cost advantage, there is the considerable added costs of writing the contract which are inherently incomplete [45] and have the added hazard costs of opportunism, inefficiencies, and disputes [2].

In both large and small IT organizations, these hunches about saving time and/or money can be directly translated into causal statements and then into analytical models. The size, nature, duration, vendor, and various other factors can be compared to the historical cost savings both before and after the outsourcing.

\subsection{Strategic implicit}

Implicit hunches were harder to discover in the interviews. Causes are generally straightforward but the effects are not clearly articulated and translating the causal statement into an analytical model is much more difficult. Twenty-three of the fifty CIOs knew that they were losing "something" in the outsourcing, and they had a hunch that they were losing domain knowledge that would be hard to recover. For example:

The guys we deal with from $X X X$ are the outsourcing experts. They're $X X X$ services. So, we did this and then Jim got promoted and Bob came in who's an IT guy and Bob said, well you can't separate maintenance and development and I think you're going to lose all kinds of IT skills.

Low overhead. Certain costs, you pay the contractor to do everything and they've got to keep track and keep up everything. I don't know. Personally, I think you lose a lot of knowledge and oversight and control and over programs if you turn that over to contractors.

While the CIOs worry about losing in-house ITrelated knowledge, a much greater concern is the loss of domain knowledge within their IT organization and the vendor's lack of domain knowledge. This was especially prevalent in the larger (more than 5000 employee) and knowledge-intensive (bank, insurance, etc.) companies.

Everything we do, and I believe every business initiative that we have is IT enabled and a fundamental part of those business initiatives is IT. But I think it's very important for us to dispel any thought process to continue outsourcing. Over there there's a whole bunch of IT people kind of sit around dreaming up IT solutions to problems that don't exist. So you combat that by really pushing hard. There are no IT initiatives. Everything we do is business related. 
I think we continue to use our own talent they are going to be less technically software computer science schooled and more business requirements focused, then going on and doing your development too. I see a lot more outsourcing taking place within the IT organization and to do that, I think we'll see a lot stronger software requirement building coming up front. Maybe that paradigm shift in our staffing is the right thing to do where we become more requirements oriented and more requirements analytical than ones and zeros on the coding side.

This is much more difficult to examine and it will require deeper analysis in the requirements documents and communications between the IT group and the vendor to see how the vendor's lack of specific (or even general) domain knowledge affects the quality of the product. Data mining and text mining along with artificial intelligence and machine learning will be invaluable tools for examining these hunches.

\subsection{Tactical explicit}

The programmer / analysts were much closer to the day-to-day operations than the CIOs. As a group, they went into much less detail in their interviews and were much less speculative in their answers. Out of 4,832 causal statements only 473 , or less than $10 \%$, were hunches. Their primary explicit hunches were about telecommuting and productivity.

[Hospital programmer / analyst]: They see no value in working away from the office and I think they are moving too slowly. Let's get a secure Intranet going so I can sign in and pull up medical records and you know, sign my dictation and do everything from the beach down in Florida, wherever I am. And they're saying, "I don't think we want to move quite that fast just yet"! There's some problems with that.

[Very large manufacturing company analyst]: They have a telecommuting program that makes life very nice. My tasks, I work from home two days a week. It is great. I think I get a lot of work done. I'm a single parent and it allows my daughter to sleep in you know, when she can in the summer time. It allows a degree of productivity that I haven't had in the past. I can work on my own schedule.

The key benefit of telecommuting is the worker's productivity. While the concept of telecommuting has been around for decades, the benefits are still an active research subject. However, workers are feeling increasingly tethered to the office by their smart phone, tablet, laptops, and other mobile devices. They are essentially "on call" twenty-four hours a day. Worker fatigue has been reported due to this "tethering."

These hunches are fairly easy to explore. Productivity can be defined through work schedules, call logs, time spent working vs. not working, assignments completed, and various other factors.

\subsection{Tactical implicit}

By far the most numerous tactical hunches were about bureaucracy and how it impacted their work.

[Very large manufacturing company]: I don't see any direction coming from the company in general. I see upper management floundering radically. The company's in great trouble. From a computing specific orientation I think we're all messed up.

[Utility company internal consultant]: I think people, in a particularly political situation where people don't meet, people in lower positions don't want to make a decision that they think their supervisor or someone in the chain would disagree with and get unhappy with. They'd rather shove the decision up the chain. Then they don't have the responsibility of doing something wrong, instead of their supervisors.

These are implicit hunches. While bureaucracy is a clear cause, the effect is difficult to discern. Organizations strive to be nimble, flexible, and innovative, but bureaucracy and red tape is "killing organizations," especially those dealing with information technology [26, 35]. Once again, data mining and text mining along with artificial intelligence can identify and resolve the causal statements into analytical results.

\section{The hunch mining model}

The hard thing about retrieving data is deciding what question to ask, not asking it. [8].

Hunch mining by hand is a tremendous amount of work. We had a very small dataset in a very limited domain. The CIO transcripts amounted to roughly 400 pages of text. The programmer / analyst transcripts covered 1,200 pages of text. In addition to dozens of hours of recording and transcribing interviews, hundreds of hours were spent identifying, extracting, and classifying causal statements, finding which statements were hunches, and then interpreting the various kinds of hunches across all the interviews.

Each interview took approximately 45 minutes, representing a small part of an average worker's day. As one rises through the corporate ranks, 
communication becomes a larger part of the day and it becomes much less structured. According to The Harvard Business Review, leadership is a conversation: "Traditional corporate communication must give way to a process that is more dynamic and more sophisticated. Most important, it must be conversational" [19, p. 77]. Unstructured informal communication is becoming the norm.

Informal executive communications, if they can be captured, are rich in hunches that can be mined. Formal communication such as mission statements, directives, press releases, and letters to investors are relatively poor sources of hunches. They are easy to obtain but they represent thoughtful communications where speculation and uncertainty is discouraged. In fact, it is often used to suppress uncertainty in the organization. Even less formal communications such as meeting notes and internal memos are washed of speculation.

However, informal often unguarded communication is heavy with speculation. Formal meetings are often recorded as a source for meeting notes, but the full recordings include discussions, comments, arguments, and speculation. Speech recognition artificial intelligence software today is powerful enough to transcribe natural language with surprising accuracy. IBM set a record of a 5.5 percent word error rate with technology that "could eventually live in smartphones and voice assistants like Siri, Alexa, and Google Assistant" [44]. Compare this with humans who have a 5.9 percent word error rate in their speech recognition. Telephone and other conversations can also be recorded and automatically transcribed for hunch mining by AI.

Tactical workers communicate less and through fewer channels than executives. Written communication "up" tends to be very formal and even verbal communication has little speculation. Even when expressly called for, speculation must be thoughtful and based on hard data. However, communication between colleagues is often dense with speculation as workers try to figure out what's going on around them. This is much more difficult to capture due to the obvious privacy concerns. We are approaching the day where all formally scheduled meetings are automatically recorded. All this data can be readied for analysis using the same methods as with executive communications. In addition, problem or project specific documentation may be rich in hunches, especially client documents.

Once captured, Artificial Intelligence can augment analytics and text mining / text analytics software to find embedded causal statements. Natural language processing is becoming increasingly sophisticated. Where speech recognition translates sounds into text, natural language processing takes text and extracts meaning. For example, IBM's Watson Artificial Intelligence engine is performing ground-breaking cancer research: A version of Watson "includes medical literature, patents, genomics, and chemical and pharmacological data that researchers would typically use in their work. Watson has also been developed with specific comprehension of scientific terminology so it can make novel connections in millions of pages of text" [10, p. 688]. It should be possible to configure Watson (or a similar powerful text analysis AI machine) with specific comprehension of corporate terminology so that it can not only identify causal statements but also make novel connections across all corporate communications. While this is now being performed on unique supercomputers, Artificial Intelligence enabled data analytics will soon be available on corporate servers or through the cloud.

Text analysis can locate the key words, phrases, and hints that find hunches. In the future, this analysis can be extended to recognize tiny facial and body language cues and subtle voice inflections that indicate that the speaker is not quite sure and is speculating about something.

But this is just the beginning of the analytics journey. From here the hunches need to be resolved into models and the models need to be used as guides for data analytics and data mining efforts. However, all this work is worth it as the results will be grounded in expert knowledge from executives (for strategic hunches) or workers (for tactical hunches). When the results are returned to the source, they can be more easily interpreted than a data mining excursion that produces "the data shows that $x$ leads to $y$ " with no real idea of why $x$ and $y$ are important or why their relationship matters.

\section{Recommendations and conclusions}

Cognitive researchers and cognitive scientists have spent millions of hours analyzing human behavior through recorded interviews, observations, and other methods. The science of cognition is an advanced science and it has created a new career specific to data analytics and artificial intelligence called cognitive computing engineer (CCE). Cognitive computing engineering is one of the three jobs in the highest demand in 2017 [39]. The job is so new that CCE responsibilities are not yet fully defined, but they include AI, machine learning, speech and text recognition, big data analysis, and modeling.

The CCE bridges the gap between academics and business practice, bringing the science of cognition into the practice of hunch mining. CCEs use theories from cognitive science, human factors, human- 
computer interaction design, and systems engineering as a foundation to design and build complex artificial intelligence enhanced analytical systems and work to improve human interactions with these complex systems [17]. The CCEs will advance hunches from being an "irrational mystical force" [5] to being a powerful tool for directing analytics.

The CCE mines the data for the tactical and strategic hunches. Figure 3 shows where the data is located both inside and outside of the organization.

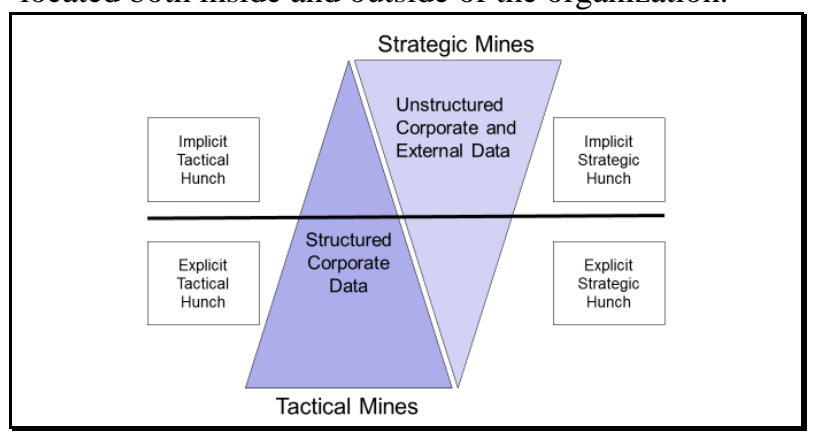

Figure 3. Data sources for hunches.

\subsection{Implications for practice.}

It's important to have the organization ready to supply the CCE with a rich collection of data. Various sources of data are outlined below.

1. Explicit Tactical Hunches are found primarily in structured corporate data with unstructured corporate data supplying some additional richness. Data sources include but are not limited to:
a. Corporate databases
b. Corporate data warehouses
c. Meeting schedules
d. Meeting notes
e. Project documentation
f. Requirements documentation

2. Implicit Tactical Hunches are found primarily in unstructured corporate data backed up by structured data. The implicit effects of the causal statements need unstructured data. Data sources include:
a. Documents
b. Notes
c. Internal communications such as texts and email
d. Databases and data warehouses

3. Explicit Strategic Hunches are found primarily in unstructured internal and unstructured external data. It is supplemented by internal structured data. Data sources include:
a. Telephone calls
b. Meeting transcriptions
c. Emails

d. Corporate documents

e. Social media

f. Newspapers and magazines

4. Implicit Strategic Hunches use unstructured corporate and external data almost exclusively. Facts and figures may rarely be added with structured corporate data.
a. Telephone calls
b. Meeting transcriptions
c. Emails
d. Corporate documents
e. Video and audio recordings
f. External media

These are all sources of data that exist in today's corporations. However, the richness of the data sets depends strongly on the corporate climate. Hunches are the mind's way of signaling that, based on experience, something is wrong or different, and here's what it is. But to be truly useful, those hunches must be able to be freely offered and freely accepted by the organization. This is often hindered by corporate hierarchy, politics, and groupthink.

For example, an IT director (who the research team collaborated with several decades) had strategic explicit and implicit hunches about a proposed Enterprise Resource Planning (ERP) system. The explicit hunch was that the 500+ person IT organization was unwilling and unable to implement the system. The explicit hunch was both observed and felt. The implicit hunch was that the company had neither sufficiently clarity of data or clarity of information streams to implement the ERP. The director could not prove it beyond the span of the IT organization they controlled.

In 1997 this type of knowledge was not reliably at hand in large corporations. The director tried several times to alert more senior executives to these potential problems and was rebuffed and threatened because political waves were not allowed. The implementation failed. Between 1997 and 2002 the company spent more than \$1 billion on this failed ERP. Between 2002 and now they tried to implement an ERP two more times. Each time they failed. Now in 2017 they are trying again.

\subsection{Implications for Research}

We used a variation on revealed causal mapping to expose hunches in open-ended interviews. Where causal mapping identifies if-then relationships in text, we extended it to degrees of speculation in the relationship. We identified "I think if-then" relationships which is useful beyond the strict number of relationships that revealed causal mapping uses. 
The data sources mentioned above work well in a business environment as they provide the context needed to categorize and focus the modeling and analytics. However, a richer source of data could be completely unstructured "stream of consciousness" context-free hunch mining.

The interviews in this study were open-ended with verbal probes. However, research indicates that thinking aloud, introspection, and stream of consciousness cognitive interview techniques allow the subjects to cover a wider range of topics and can be a more authentic reflection of the subjects' thought processes [33].

Speech recognition, text analysis, and AI can speed the process of finding hunches that can be explored later with automated business analytics.

Hunch mining is a method to bring cognitive science into the organization. In addition to the structed data that corporations hold within their data warehouses, adding both text and voice data will enhance the chances of hunch mining accessing into the individual decision maker's intuition. Cognitive Computing Engineers will have to work with corporate leaders to create a politically safe environment for hunches that question conventional wisdom and favored corporate direction.

If companies want to be efficient, effective, innovative, and nimble they need to understand the power of hunches. Hunch mining could potentially save billions of dollars or in the field of medicine, actual lives.

\section{References}

[1] Agor, W. A., "The Logic of Intution: How Top Executives Make Important Decisions," Organizational Dynamics, vol. 14, 1986pp. 5-18.

[2] Ang, S. and Straub, D., "Production and Transaction Economies and IS Outsourcing: A Study of the U.S. Banking Industry," MIS Quarterly, vol. 22, 1998pp. 535-552.

[3] Axelrod, R., Ed., Structure of Decision: The Cognitive Maps of Political Elites. Princeton, NJ: Princeton University Press, 1976, p.^pp. Pages.

[4] Bartlett, F. C., Remembering: A Study in Experimental and Social Psychology. Cambridge: University Press, 1932.

[5] Bergson, H., Creative Evolution. New York: Henry Holt, 1911.

[6] Betts, S. C., "Lucky Rolls, Leaps of Faith and Hunches: Luck, Faith, and Intution in Decision Making," Business Studies Journal, vol. 3, 2011pp. 77-87.

[7] Boeing. (2017, June 14, 2017). Available: http://www.boeing.com/company/bios/
[8] Brooks, F. (1987) No Silver Bullet: Essence and Accidents of Software Engineering. IEEE Computer Magazine. 10-19.

[9] Chang, Y. B. and Gurbaxani, V., "Information Technology Outsourcing, Knowledge Transfer, and Firm Prodoctivity: An Empirical Analysis," MIS Quarterly, vol. 36, 2012pp. 1043-1063.

[10] Chen, Y., Argentinis, J. E., and Weber, G., "IBM Watson: How Cognitive Computing Can Be Applied to Big Data Challenges in Life Sciences Research," Clinical Therapeutics, vol. 38, 2016pp. 688-701.

[11] Dane, E. and Pratt, M. G., "Exploring Intuition and Its Role in Managerial Decision Making," Academy of Management Review, vol. 32, 2007pp. 33-54.

[12] Davenport, T., "Keep Up with Your Quants," Harvard Business Review, vol. 91, 2013pp. 120123.

[13] Davenport, T., "The Rise of Automated Analytics," in The Wall Street Journal, ed, 2015.

[14] Davenport, T. (2015). Industrialized Analytics: Implications of Large-Scale Predictive Analytics Models. Available:

https://dupress.deloitte.com/dup-usen/topics/analytics/large-scale-predictiveanalytics-models.html

[15] Festinger, L., A Theory of Cognitive Dissonance. Stanford, CA: Stanford University Press, 1957.

[16] Fiol, C. M. and Huff, A. S., "Maps for Managers: Where Are We? Where do We Go From Here?," Journal of Management Studies, vol. 29, 1992pp. 267-285.

[17] Gersh, J. R., McKneely, J. A., and Remington, R. W., "Cognitive Engineering: Understanding Human Interaction with Complex Systems," Johns Hopkinds APL Technical Digest, vol. 26, 2005pp. 377-482.

[18] Griffin, K., Fundamentals of Management. New York: Houghton Mifflin, 2007.

[19] Groysbert, B. and Slind, M., "Leadership is a Conversation," Harvard Business Review, 2012pp. 76-84.

[20] Han, K. and Mithas, S., "Information Technology Outsourcing and Non-IT Operating Costs: An Empirical Investigation," MIS Quarterly, vol. 37, 2013pp. 315-331.

[21] Khatri, N. and Ng, H. A., "Thr Role of Intution in Strategic Decision Making," Human Relations, vol. 53, 2000pp. 57-86.

[22] Lerner, C. S., "Reasonable Suspicion and Mere Hunches," Vanderbilt Law Review, vol. 59, 2006pp. 407-473.

[23] Lufityanto, G., Donkin, C., and Pearson, J., "Measuring Intuition: Nonconscious Information 
Boosts Decision Accuracy and Confidence," Psychological Science, vol. 27, 2016pp. 622-634.

[24] Lussier, K., "Managing Intuition," Business History Review, vol. 90, 2016pp. 708-718.

[25] Malewska, K., "Intuition in Decision Making -Theoretical and Empirical Aspects," International Journal of Buisiness and Economic Development, vol. 3, 2015pp. 97-105.

[26] Moon, M. J. and Bretschneider, S., "Does the Perception of Red Tape Constrain IT Innovativeness in Organizations? Unexpected Results from a Simultaneous Equation Model and Implications," Journal of Public Administration Research \& Theory, vol. 12, 2002pp. 273-292.

[27] Narayanan, V. K. and Fahey, L., "Evolution of Revealed Causal Maps During Decline: A Case Study of Admiral," in Mapping Strategic Thought, A. Huff, Ed., ed London: John Wiley and Sons, 1990, pp. 109-134.

[28] Nelson, K. M., Nadkarni, S., Narayanan, V. K., and Ghods, M., "Understanding Software Operations Support Expertise: A Revealed Causal Mapping Approach," MIS Quarterly, vol. 24, 2000pp. 475-507.

[29] Nonaka, I., "A Dynamic Theory of Organizational Knowledge Creation.," Organization Science, vol. 5, February 1994pp. 14-37.

[30] Pennington, N., "Stimulus structures and mental representations in expert comprehension of computer programs," Cognitive Psychology, 1987pp. 295-341.

[31] Peters, T. H. and Waterman, R. H., In Search of Excellence: Lessons from America's Best-Run Companies. New York: Harper \& Row, 1982.

[32] Preece, J., Rogers, Y., Sharp, H., Benyon, D., Holland, S., and Carey, T., "Knowledge and Mental Models," in Human-Computer Interaction, ed Wokingham, England: AddisonWesley, 1994, p. 69.

[33] Priede, C. and Farrall, S., "Comparing results from different styles of cognitive interviewing: 'verbal probing' vs. 'thinking aloud'," International Journal of Social Research Methology, vol. 14, 2011pp. 271-287.

[34] Provis, C., "Intuition, Analysis, and Reflection in Business Ethics," Journal of Business Ethics, vol. 140, 2017pp. 5-15.

[35] Ranjekar, D., "Is Bureaucracy Killing Organizations?," Human Capital, vol. 18, 2015pp. 8-9.

[36] Rossi, P. H., Wright, J. D., and Anderson, A. B., Handbook of Research Methods. Orlando, FL: Academic Press, 1983.
[37] Sadler-Smith, E. and Shefy, E., "The intuitive executive: Understanding and applying "gut feel" in decision-making," academy of Management Executive, vol. 18, 2004pp. 76-91.

[38] Sauter, V. L., "Intuitive Decision Making," Communications of the ACM, vol. 42, 1999pp. 109-115.

[39] Scorsone, G., "New Tech Jobs in Top Demand in 2017," Network World, 2016.

[40] Soter, A. O., Wilkinson, I. A., Murphy, P. K., Rudge, L., Reninger, K., and Edwards, M., "What the Discourse Tells Us: Talk and Indicators of High-Level Comprehension," International Journal of Educational Research, vol. 47, 2008pp. 372-391.

[41] Tollin, K., "Mindsets in Marketing for Product Innovation: An Explorative Analysis of Chief Marketing Executives' Ideas and Beliefs about How to Increase Their Firms' Innovation Capability," Journal of Strategic Marketing, vol. 16, 2008pp. 363-390.

[42] Vahn, G.-Y., "Business Analytics in the Age of Big Data," Business Strategy Review, vol. 25, 2014pp. 8-9.

[43] Vandenbosh, B. and Higgins, C., "Information Acquisition and Mental Models: An Investigation into the Relationship Between Behavior and Learning," Information Systems Research, vol. 7, June 1996pp. 198-214.

[44] Weller, C., "IBM Speech Recognition is on the Verge of Super-Human Accuracy," Business Insider, 2017.

[45] Williamson, O. E., "Transaction cost economics: The governance of contractual relations," Journal of Law and Economics, vol. 22, 1979pp. 233-261. 